\title{
Skeletal muscle contraction-induced vasodilation in the microcirculation
}

\author{
Kwang-Seok Hong', Kijeong Kim ${ }^{2 * *}$ \\ ${ }^{1}$ Robert M. Berne Cardiovascular Research Center, University of Virginia-School of Medicine, Charlottesville, VA, USA \\ ${ }^{2}$ School of Exercise \& Sport Science, College of Natural Sciences, University of Ulsan, Ulsan, Korea
}

Maximal whole body exercise leads skeletal muscle blood flow to markedly increase to match metabolic demands, a phenomenon termed exercise hyperaemia that is accomplished by increasing vasodilation. However, local vasodilatory mechanisms in response to skeletal muscle contraction remain uncertain. This review highlights metabolic vasodilators released from contracting skeletal muscle, endothelium, or blood cells. As a considerable skeletal muscle vasodilation potentially results in hypotension, sympathetic nerve activity needs to be augmented to elevate cardiac output and blood pressure during dynamic exercise. However, since the enhanced sympathetic vasoconstriction restrains skeletal muscle blood flow, intramuscular arteries have an indispensable ability to blunt sympathetic activity for exercise hyperaemia. In addition, we discuss that mechanical compression of the intramuscular vasculature contributes to causing the initial phase of increasing vasodilation following a single muscle contraction. We have also chosen to focus on conducted (or ascending) electrical signals that evoke vasodilation of proximal feed arteries to elevate blood flow in the microcirculation of skeletal muscle. Endothelial hyperpolarization originating within distal arterioles ascends into the proximal feed arteries, thereby increasing total blood flow in contracting skeletal muscle. This brief review summarizes molecular mechanisms underlying the regulation of skeletal muscle blood flow to a single or sustained muscle contraction.

Keywords: Blood flow control, Endothelium, Exercise hyperaemia, Intramuscular vasculature, Microcirculation, Vascular smooth muscle cell

\section{INTRODUCTION}

During steady-state dynamic exercise, blood flow to active skeletal muscle is dramatically increased by nearly 100 times (i.e., exercise hyperaemia) (Richardson et al., 1993). Skeletal muscle blood flow is regulated by metabolic vasodilatory substances (Clifford and Hellsten, 2004). Furthermore, increased sympathetic nerve activity that causes vasoconstriction in 'noncontracting' skeletal muscle to prevent hypotension is interestingly reduced in 'contracting' skeletal muscle to increase vasodilation and provide adequate blood flow during exercise (Hearon and Dinenno, 2016). A number of leading investigators have also attempted to demonstrate how skeletal muscle vasodilation is initiated from a single muscular contraction. Potential mechanisms such as acetylcholine (ACh) spillover, potassium release following skeletal muscle con- traction, mechanosensitive component-induced vasodilation, and conducted vasodilation would be discussed in this review.

\section{METABOLIC VASODILATORY FACTORS}

Nitric oxide (NO), an endogenous vasoactive candidate, is generated by endothelial nitric oxide synthase or neuronal nitric oxide synthase (nNOS) in the endothelium or skeletal muscle cells, respectively (Frandsen et al., 1996; Grozdanovic et al., 1996). Since exercise-induced increases in endogenous agonists (e.g., ACh, bradykinin, and adenosine triphosphate [ATP]) elicit NO generation (Nosarev et al., 2015), NO seems to play a crucial role in vasodilation in contacting skeletal muscle. However, roles of NO in exercise hyperaemia are still far from clear. Prior studies have been shown that pharmacological inhibition of NOS with L-NAME
${ }^{*}$ Corresponding author: Kijeong Kim (iD https://orcid.org/0000-0001-9233-3096 School of Exercise \& Sport Science, College of Natural Sciences, University of Ulsan, 93 Daehak-ro, Nam-gu, Ulsan 44610, Korea

Tel: +82-52-259-2381, Fax: +82-52-259-1696, E-mail: kijeongk@ulsan.ac.kr Received: September 13, 2017 / Accepted: October 8, 2017
This is an Open Access article distributed under the terms of the Creative Commons Attribution Non-Commercial License (http://creativecommons.org/licenses/by-nc/4.0/) which permits unrestricted non-commercial use, distribution, and reproduction in any medium, provided the original work is properly cited. 
does not diminish vasodilation of skeletal muscle arteries in contracting leg muscle (Frandsenn et al., 2001; Rådegran and Saltin, 1999), indicating that NO may be a nonobligatory molecule for exercise hyperaemia. Contrarily, it has been reported that skeletal muscle contraction leads matricryptic type II repeat of fibronectin (FNIII-1) receptors on vascular smooth muscle cells (VSMCs) to be exposed, inducing NO-mediated vasodilation by stimulating nNOS (Hocking et al., 2008). Collectively, further studies are required for a better understanding of $\mathrm{NO}$ in exercise hyperaemia.

Prostaglandin $\mathrm{E}_{2}$ and prostacyclin $\left(\mathrm{PGI}_{2}\right)$ are derived from prostaglandin $\mathrm{H}_{2}$ that is converted from arachidonic acid through cyclooxygenase (COX). These prostaglandins are commonly generated from endothelium or skeletal muscle cells (Davidge, 2001). Exercise is shown to increase levels of prostaglandin $\mathrm{E}_{2}$ and $\mathrm{PGI}_{2}$ in the interstitial space or venous efflux of contracting skeletal muscle (Frandsen et al., 2000). However, similar to NO, some debates exist as to whether prostaglandins are involved in exercise hypereamia. Once COX inhibitors were infused to reduce prostaglandin production, blood flow of human forearm and leg was not considerably altered at rest or during exercise (Schrage et al., 2004; Schrage et al., 2010). Interestingly, simultaneous suppression of COX and NOS reduced blood flow in the exercise leg by $30 \%$ (Schrage et al., 2004), suggesting that NO-dependent vasodilation may compensate for COX inhibition-mediated decrease in vasomotor reactivity to provide adequate blood flow during exercise.

The fact that each skeletal muscle is innervated by a motor nerve at the neuromuscular junction suggests the intriguing hypothesis that ACh spillover results in skeletal muscle arteriolar vasodilation (Welsh and Segal, 1997). ACh released from the end plate of motor nerves stimulates nicotinic receptors on the sarcolemma to elicit muscle contraction. ACh spillover is sufficient to functionally reach small-sized arteries and capillaries in skeletal muscle for vasodilation (Welsh and Segal, 1997). ACh directly binds to muscarinic receptors in endothelial cells (ECs) and in turn alters intracellular $\mathrm{Ca}^{2+}$ dynamics including $\mathrm{Ca}^{2+}$ release from the endoplasmic reticulum (ER). These $\mathrm{Ca}^{2+}$ signaling networks provoke $\mathrm{NO}$ production and endothelium-derived hyperpolarization $(\mathrm{EDH})$ that are responsible for a prompt vasodilation following a brief muscle contraction or during exercise. However, the 'ACh spillover' has been debated and questioned in subsequent studies. Blood flow in response to muscle contraction was assessed in the absence or presence of atropine (nicotinic receptor antagonist) that would not suppress ACh release but would inhibit muscle contraction (Brock et al., 1998). As a consequence, the atropine application did not abolish increased vasodilation and blood flow after forearm muscle contraction. Further, pharmacological neuromuscular blockade with vecuronium (for inhibition of muscle contraction) profoundly attenuated increases in vasodilation and blood flow following a single or repeated muscle contraction (Naik et al., 1999). These results suggest that ACh spillover from the motor nerves may not be necessary for muscle contraction-induced vasodilation. Preferably, vasoactive substances released/produced by muscle contraction may play an important role in increasing vasomotor reactivity and blood flow.

Several criteria have been established to determine whether endogenous molecules act as metabolic vasodilatory factors during physiological stresses (Feigl, 1983): (a) the endogenous candidates that regulate vasomotor reactivity at rest or during exercise have to be measurable; (b) the vasoactive responses similarly or identically occur when the candidate agents are exogenously applied; and (c) stimulating or inhibiting vascular responses to the vasodilatory molecules has to be consistent. On the basis of the criteria, substantial attention has been paid to intravascular ATP as a potent vasodilatory molecule in contracting skeletal muscle. Indeed, ATP concentration in venous plasma draining from skeletal muscle was progressively and considerably elevated along with increasing intensity of rhythmic handgrip contraction or single-leg knee extensor exercise (Mortensen et al., 2011; Kirby et al., 2012). ATP-mediated activation of purinergic $\left(\mathrm{P}_{2}\right)$ receptors in ECs evokes a roust vasodilation during exercise through protein kinase $\mathrm{C}$ (PKC)-AktNO signaling pathways (Mortensen et al., 2009a). The increased ATP has been identified to be rapidly degraded by ectonucleotideases ( $<1$ sec of half-life), implicating that ATP should be locally released in the microcirculation to promptly cause vasodilation during exercise (Crecelius et al., 2015). Regarding to the cellular sources of ATP, it was conventionally predicted that ATP is likely released from sympathetic nerves or contracting skeletal muscle itself (Mortensen et al., 2009b). However, exogenous ATP administration does not alter interstitial ATP levels (Mortensen et al., 2009b). It is implied that sympathetic nerve and/or skeletal muscle-released ATP may not be able to pass across the plasma membrane of VSMCs and exert endothelial $\mathrm{P}_{2}$ receptor-mediated vasodilation (Crecelius et al., 2015). On the other hand, previous studies have elucidated that perfusion occlusion markedly diminishes exercise-induced increase in venous plasma ATP concentration (Kirby et al., 2013), suggesting that the increased ATP from steady-state exercise is closely related to elevated intravascular perfusion. As the increased perfusion augments blood supply and shear stress, a general belief is that the sources of ATP release during exercise may be erythrocytes and/or endothelial cells. 
In general, potassium $\left(\mathrm{K}^{+}\right)$is the most abundant ion in cells and $\mathrm{K}^{+}$channels largely regulate the membrane potential (Haddy et al., 2006). Since intracellular $\mathrm{K}^{+}$concentration is much higher than one in extracellular space, this chemical gradient result in $\mathrm{K}^{+}$ efflux and more negative membrane potential (i.e., hyperpolarization or repolarization). It is important to note that $\mathrm{K}^{+}$ions are released from contracting skeletal muscle fibers for the repolarization phase of the contraction/relaxation cycle (Clifford, 2007). Previous studies support the notion that interstitial $\mathrm{K}^{+}$levels are profoundly increased following a single muscle contraction (Hnik et al., 1976) or during exercise (Green et al., 2000; Juel et al., 2000; Lott et al., 2001). Interestingly, alteration in interstitial $\mathrm{K}^{+}$ concentration is dependent of exercise duration (Hnik et al., 1976) or intensity (Green et al., 2000) of skeletal muscle contraction. $\mathrm{K}^{+}$ released from skeletal muscle fibers is considered a key player for vasodilation or exercise hyperaemia by inducing $\mathrm{K}^{+}$channel activation-dependent hyperpolarization of VSMCs (Joyner and Wilkins, 2007). Specifically, inwardly rectifying $\mathrm{K}^{+}\left(\mathrm{K}_{\text {ir }}\right)$ channels are activated by increased extracellular $\mathrm{K}^{+}$to cause $\mathrm{K}^{+}$efflux-mediated hyperpolarization (Knot et al., 1996). While the relatively high $\mathrm{K}^{+}$provokes vasoconstriction through $\mathrm{K}^{+}$entry through $\mathrm{K}_{\mathrm{ir}}$ channels expressed in VSMCs (Quayle et al., 1993) based on the Nernst equation, $\mathrm{K}_{\text {ir }}$ channels stimulated by the low $\mathrm{K}^{+}$level result in $\mathrm{K}^{+}$efflux and vasodilation (Knot et al., 1996). It has been defined in animal and human studies that vasodilation following a single skeletal muscle contraction or during steady-state exercise is significantly abrogated in the presence of $\mathrm{K}_{\text {ir }}$ channel inhibitor barium chloride (Armstrong et al., 2007; Crecelius et al., 2014). Thus, extracellular $\mathrm{K}^{+}$and $\mathrm{K}_{\mathrm{ir}}$ channel-mediated VSMC hyperpolarization and vasodilation is a novel and innovative mechanism underlying onset and steady-state exercise hyperaemia.

\section{FUNCTIONAL SYMPATHOLYSIS}

Skeletal muscle blood flow increases significantly during wholebody maximal exercise, which exceeds the pumping capacity of the heart and causes excessive vasodilation-mediated hypotension (Hearon and Dinenno, 2016). Thus, during high intensity exercise, sympathetic nerve activity has to be markedly enhanced to elevate cardiac output and peripheral vasoconstriction through the binding of norepinephrine to $\boldsymbol{\alpha}_{1}$ - and $\boldsymbol{\alpha}_{2}$-adrenergic receptors in VSMCs (Thomas, 2015). The increased sympathetic nerve activity contributes to regulation of systemic blood pressure and redistribution of cardiac output towards contracting skeletal muscle (Hearon and Dinenno, 2016). However, in contrast to inactive tissues, peripheral vasoconstriction signaling in response to sympathetic nerve activity should be attenuated in vascular beds of contracting skeletal muscle to optimize blood flow and oxygen delivery during exercise, which is termed 'functional sympatholysis' (Remensnyder et al., 1962).

Although the exact mechanisms underlying functional sympatholysis remain unclear, mounting evidence has shown that it is regulated by a number of local vasoactive substances including NO, prostaglandins, ATP, and $\mathrm{K}^{+}$ions (Clifford and Hellsten, 2004; Saltin and Mortensen, 2012). In addition, functional sympatholysis is directly proportional to exercise intensity (Thomas and Segal, 2004) and primarily occurs in the small distal arterioles compared to the proximal arteries or feed arteries in the skeletal muscle microcirculation (VanTeeffelen and Segal, 2003). This heterogeneity in functional sympatholysis leads the distal arterioles to ensure adequate blood flow to the most metabolically active skeletal muscle (Thomas, 2015). Meanwhile, impaired functional sympatholysis is associated with vascular diseases such as hypertension (Thomas, 2015) and sympathetic overactivity considerably abolishes skeletal muscle vasodilation during exercise (Calbet and Lundby, 2012). Taken together, appropriate functional sympatholysis contributes to regulating blood flow distribution in contracting skeletal muscle.

\section{MECHANICAL COMPRESSION}

A large number of studies have investigated vasodilatory mechanisms during steady-state muscle contraction. However, these mechanisms do not account for a fundamental question as to how the vasodilation of skeletal muscle feed arteries or arterioles are initiated at the onset of muscle contraction. With respect to this interesting issue, emphasis has been placed on external compression (elicited by muscle contraction) on intramuscular arterioles. It has been reported that intramuscular pressures of 270 or 600 $\mathrm{mmHg}$ are observed during moderate-intensity running or maximal muscle contraction, respectively (Ballard et al., 1998; Sejersted et al., 1984). As ECs and VSMCs are mechanosensitive to shear stress, stretch, tension, or pressure, it is conceivable that muscle contraction-evoked mechanical compression may activate mechanosensors in ECs or VSMCs to initiate vasodilation following a brief muscle contraction.

Clifford et al. (2006) attempted to directly explore this intriguing hypothesis by manipulating extravascular pressure in a custom-designed chamber that mimics mechanical compression caused by skeletal muscle activity. Pressure pulses of $600 \mathrm{mmHg}$ were applied on isolated rat soleus feed arteries for $1 \mathrm{sec}, 5 \mathrm{sec}$, or a 
series of 5 repetitions with 1 -sec duration. While the skeletal muscle feed arteries were entirely collapsed during the extravascular pressure application, release of the pressure immediately led to a significant vasodilation (Clifford et al., 2006). The degree of vasodilation was independent of the duration of compression, whereas increasing the number of compressions markedly augmented vasodilation in soleus feed arteries (Clifford et al., 2006). Consistently, it has been shown in human studies that elevation in extravascular pressure significantly increases blood flow and vascular conductance in forearm brachial arteries (Kirby et al., 2007). Recent work has mechanistically identified that blockade of integrins (mechanosensors in ECs and VSMCs) with antibodies against $\alpha_{5} \beta_{1} \alpha_{v} \beta_{3}$ integrins significantly diminishes mechanical compression-evoked vasodilation of intramuscular arteries (Lu and Kassab, 2015).

\section{ENDOTHELIUM-DERIVED HYPERPOLARIZATION AND CONDUCTED VASODILATION}

Endothelial $\mathrm{Ca}^{2+}$ signaling plays an essential role in regulating vascular diameter and blood flow by changing membrane potential in ECs and VSMCs (Garland et al., 2011). ACh-dependent activation of endothelial muscarinic receptors stimulates phospholipase $C$ to induce cleavage of phosphatidylinositol 4,5-bisphosphate into diacylglycerol and inositol 1,4,5-trisphosphate ( $\left.\mathrm{IP}_{3}\right)$. The binding of the second messenger to $\mathrm{IP}_{3}$ receptors (IP $\left.\mathrm{IP}_{3} \mathrm{R}\right)$ in ER results in $\mathrm{Ca}^{2+}$ release from the ER. The released $\mathrm{Ca}^{2+}$ activates intermediate/small conductance $\mathrm{Ca}^{2+}$-sensitive $\mathrm{K}^{+}$channels $\left(\mathrm{IK}_{\mathrm{Ca}} /\right.$ $\mathrm{SK}_{\mathrm{C}_{\mathrm{a}}}$ ) and leads to $\mathrm{K}^{+}$efflux. The $\mathrm{K}^{+}$loss elicits $\mathrm{EDH}$ that is transferred to VSMCs through myoendothelial gap junctions (MEGJs). MEGJs are indispensable for EC-SMC heterocellular communication that allows the movement of ionic charges between those cells (Figueroa and Duling, 2009). The hyperpolarization to VSMCs causes vasodilation by suppressing $\mathrm{Ca}^{2+}$ influx through voltage dependent calcium channels (VDCCs) that are required for vasoconstriction. ACh-induced VSMC hyperpolarization and vasodilation in small-sized arteries or arterioles were not significantly abolished in the presence of inhibitors of NO, guanylyl cyclase, or prostaglandins (Garland and McPherson, 1992). In contrast, ACh-dependent vasodilation was completely abrogated when $\mathrm{IK}_{\mathrm{Ca}}$ and $\mathrm{SK}_{\mathrm{Ca}}$ were simultaneously inhibited (Holzmann et al., 1994). These previous results indicate that vasodilatory mechanisms are primarily dependent of EDH in small-sized resistance arteries.

Arteriolar networks in skeletal muscle are typically comprised of feed arteries and branch arterioles including first-, second-, third-order, and terminal arterioles. While distal branch arterioles are embedded in skeletal muscle, proximal feed arteries are not directly involved in blood flow delivery necessary for muscle contraction. However, vasodilation along and among feed arteries and branches of vascular resistance network has to be coordinated to supply substantial blood flow into active skeletal muscle during exercise (Segal and Duling, 1986; Segal and Jacobs, 2001). It should be recognized that vasomotor reactivity of intramuscular distal arterioles are regulated by metabolic vasoactive factors, blunted sympathetic nerve activity, and dilatory mechanisms elicited by mechanical compression. From this perspective, a compelling question has been suggested: how are proximal feed arteries dilated to provide appropriate blood flow during skeletal muscle contraction? Regarding to this, the concept of 'ascending or conducted vasodilation' has shed novel insight into the coordinated vasodilation of skeletal muscle vasculature. In brief, vasodilation originating from the microcirculation embedded in skeletal muscle ascends into proximal feed arteries to increase total blood flow entering the skeletal muscle (Bagher and Segal, 2011). Accumulating evidence has shown that ascending vasodilation is attributed to the conduction of electrical signaling including EDH between EC-EC and EC-SMC through gap junctions (Segal and Duling, 1986; Segal and Jacobs, 2001). EDH initiated from the intramuscular vasculature is bi-directionally (i.e., up- and downstream) conducted from EC to EC through homocellular gap junctions (Domeier and Segal, 2007; Milkau et al., 2010). EDH is also transmitted to adjacent VSMCs through MEGJs, which in turn induces ascending vasodilation by inhibiting $\mathrm{Ca}^{2+}$ influx through VDCCs (Figueroa and Duling, 2008; Segal and Duling, 1986). Taken together, it is suggested that $\mathrm{EDH}$-mediated conducted (or ascending) vasodilation from terminal arterioles to feed arteries is a major determinant for achieving appropriate muscle blood flow during exercise.

\section{CONCLUSIONS}

An ability to elevate blood flow within the skeletal muscle microcirculation plays a vital role in matching metabolic demands and eliminating waste products of muscle metabolism. As blood flow is related to the fourth power of arterial diameter (the Pouiselle's Law), we have sought to summarize multiple vasodilatory mechanisms including metabolic, neuronal, mechanical, and conducted responses of intramuscular vasculature to muscle contraction. However, while the individual mechanism has been well defined, the mechanisms by which those contributors to vasodilation are coordinated each other to achieve optimal blood flow during 
dynamic exercise have not been fully delineated. Therefore, further studies have to be done to address integrative dilatory mechanisms in the microcirculation of skeletal muscle tissue.

\section{CONFLICT OF INTEREST}

No potential conflict of interest relevant to this article was reported.

\section{REFERENCES}

Armstrong ML, Dua AK, Murrant CL. Potassium initiates vasodilatation induced by a single skeletal muscle contraction in hamster cremaster muscle. J Physiol 2007;581(Pt 2):841-852.

Bagher P, Segal SS. Regulation of blood flow in the microcirculation: role of conducted vasodilation. Acta Physiol (Oxf) 2011;202:271-284.

Ballard RE, Watenpaugh DE, Breit GA, Murthy G, Holley DC, Hargens AR. Leg intramuscular pressures during locomotion in humans. J Appl Physiol (1985) 1998;84:1976-1981.

Brock RW, Tschakovsky ME, Shoemaker JK, Halliwill JR, Joyner MJ, Hughson RL. Effects of acetylcholine and nitric oxide on forearm blood flow at rest and after a single muscle contraction. J Appl Physiol (1985) 1998;85:2249-2254.

Calbet JA, Lundby C. Skeletal muscle vasodilatation during maximal exercise in health and disease. J Physiol 2012;590:6285-6296.

Clifford PS. Skeletal muscle vasodilatation at the onset of exercise. J Physiol 2007;583(Pt 3):825-833.

Clifford PS, Hellsten Y. Vasodilatory mechanisms in contracting skeletal muscle. J Appl Physiol (1985) 2004;97:393-403.

Clifford PS, Kluess HA, Hamann JJ, Buckwalter JB, Jasperse JL. Mechanical compression elicits vasodilatation in rat skeletal muscle feed arteries. J Physiol 2006;572(Pt 2):561-567.

Crecelius AR, Kirby BS, Dinenno FA. Intravascular ATP and the regulation of blood flow and oxygen delivery in humans. Exerc Sport Sci Rev 2015;43:5-13.

Crecelius AR, Luckasen GJ, Larson DG, Dinenno FA. KIR channel activation contributes to onset and steady-state exercise hyperemia in humans. Am J Physiol Heart Circ Physiol 2014;307:H782-791.

Davidge ST. Prostaglandin H synthase and vascular function. Circ Res 2001;89:650-660.

Domeier TL, Segal SS. Electromechanical and pharmacomechanical signalling pathways for conducted vasodilatation along endothelium of hamster feed arteries. J Physiol 2007;579(Pt 1):175-186.

Feigl EO. Coronary physiology. Physiol Rev 1983;63:1-205.

Figueroa XF, Duling BR. Dissection of two Cx37-independent conducted vasodilator mechanisms by deletion of $\mathrm{Cx} 40$ : electrotonic versus regenerative conduction. Am J Physiol Heart Circ Physiol 2008;295: H2001-2007.

Figueroa XF, Duling BR. Gap junctions in the control of vascular function. Antioxid Redox Signal 2009;11:251-266.

Frandsen U, Bangsbo J, Langberg H, Saltin B, Hellsten Y. Inhibition of nitric oxide synthesis by systemic $\mathrm{N}^{\mathrm{G}}$-monomethyl-L-arginine administration in humans: effects on interstitial adenosine, prostacyclin and potassium concentrations in resting and contracting skeletal muscle. J Vasc Res 2000;37:297-302.

Frandsenn U, Bangsbo J, Sander M, Höffner L, Betak A, Saltin B, Hellsten $Y$. Exercise-induced hyperaemia and leg oxygen uptake are not altered during effective inhibition of nitric oxide synthase with $\mathrm{N}^{\mathrm{G}}$-nitro-L-arginine methyl ester in humans. J Physiol 2001;531(Pt 1):257-264.

Frandsen U, Lopez-Figueroa M, Hellsten Y. Localization of nitric oxide synthase in human skeletal muscle. Biochem Biophys Res Commun 1996;227:88-93.

Garland CJ, Hiley CR, Dora KA. EDHF: spreading the influence of the endothelium. Br J Pharmacol 2011;164:839-852.

Garland CJ, McPherson GA. Evidence that nitric oxide does not mediate the hyperpolarization and relaxation to acetylcholine in the rat small mesenteric artery. Br J Pharmacol 1992;105:429-435.

Green S, Langberg H, Skovgaard D, Bulow J, Kjaer M. Interstitial and arterial-venous $\left[\mathrm{K}^{+}\right]$in human calf muscle during dynamic exercise: effect of ischaemia and relation to muscle pain. J Physiol 2000;529 Pt 3:849-861.

Grozdanovic Z, Gosztonyi G, Gossrau R. Nitric oxide synthase I (NOS-I) is deficient in the sarcolemma of striated muscle fibers in patients with Duchenne muscular dystrophy, suggesting an association with dystrophin. Acta Histochem 1996;98:61-69.

Haddy FJ, Vanhoutte PM, Feletou M. Role of potassium in regulating blood flow and blood pressure. Am J Physiol Regul Integr Comp Physiol 2006;290:R546-552.

Hearon CM Jr, Dinenno FA. Regulation of skeletal muscle blood flow during exercise in ageing humans. J Physiol 2016;594:2261-2273.

Hnik P, Holas M, Krekule I, Kŭriz N, Mejsnar J, Smiesko V, Ujec E, Vyskocil F. Work-induced potassium changes in skeletal muscle and effluent venous blood assessed by liquid ion-exchanger microelectrodes. Pflugers Arch 1976;362:85-94.

Hocking DC, Titus PA, Sumagin R, Sarelius IH. Extracellular matrix fibronectin mechanically couples skeletal muscle contraction with local vasodilation. Circ Res 2008;102:372-379.

Holzmann S, Kukovetz WR, Windischhofer W, Paschke E, Graier WF. Pharmacologic differentiation between endothelium-dependent relaxations sensitive and resistant to nitro-L-arginine in coronary arteries. J 
Cardiovasc Pharmacol 1994;23:747-756.

Joyner MJ, Wilkins BW. Exercise hyperaemia: is anything obligatory but the hyperaemia? J Physiol 2007;583(Pt 3):855-860.

Juel C, Pilegaard H, Nielsen JJ, Bangsbo J. Interstitial $\mathrm{K}^{+}$in human skeletal muscle during and after dynamic graded exercise determined by microdialysis. Am J Physiol Regul Integr Comp Physiol 2000;278:R400406.

Kirby BS, Carlson RE, Markwald RR, Voyles WF, Dinenno FA. Mechanical influences on skeletal muscle vascular tone in humans: insight into contraction-induced rapid vasodilatation. J Physiol 2007;583(Pt 3):861-874.

Kirby BS, Crecelius AR, Richards JC, Dinenno FA. Sources of intravascular ATP during exercise in humans: critical role for skeletal muscle perfusion. Exp Physiol 2013;98:988-998.

Kirby BS, Crecelius AR, Voyles WF, Dinenno FA. Impaired skeletal muscle blood flow control with advancing age in humans: attenuated ATP release and local vasodilation during erythrocyte deoxygenation. Circ Res 2012;111:220-230.

Knot HJ, Zimmermann PA, Nelson MT. Extracellular K+-induced hyperpolarizations and dilatations of rat coronary and cerebral arteries involve inward rectifier $\mathrm{K}^{+}$channels. J Physiol 1996;492(Pt 2):419-430.

Lott ME, Hogeman CS, Vickery L, Kunselman AR, Sinoway LI, MacLean DA. Effects of dynamic exercise on mean blood velocity and muscle interstitial metabolite responses in humans. Am J Physiol Heart Circ Physiol 2001;281:H1734-1741.

Lu X, Kassab GS. Integrins mediate mechanical compression-induced endothelium-dependent vasodilation through endothelial nitric oxide pathway. J Gen Physiol 2015;146:221-232.

Milkau M, Köhler R, de Wit C. Crucial importance of the endothelial $\mathrm{K}^{+}$ channel SK3 and connexin40 in arteriolar dilations during skeletal muscle contraction. FASEB J 2010;24:3572-3579.

Mortensen SP, González-Alonso J, Bune LT, Saltin B, Pilegaard H, Hellsten Y. ATP-induced vasodilation and purinergic receptors in the human leg: roles of nitric oxide, prostaglandins, and adenosine. Am J Physiol Regul Integr Comp Physiol 2009a;296:R1140-1148.

Mortensen SP, González-Alonso J, Nielsen JJ, Saltin B, Hellsten Y. Muscle interstitial ATP and norepinephrine concentrations in the human leg during exercise and ATP infusion. J Appl Physiol (1985) 2009b;107: $1757-1762$

Mortensen SP, Thaning P, Nyberg M, Saltin B, Hellsten Y. Local release of ATP into the arterial inflow and venous drainage of human skeletal muscle: insight from ATP determination with the intravascular microdialysis technique. J Physiol 2011;589(Pt 7):1847-1857.

Naik JS, Valic Z, Buckwalter JB, Clifford PS. Rapid vasodilation in response to a brief tetanic muscle contraction. J Appl Physiol (1985) 1999;87:1741-1746.
Nosarev AV, Smagliy LV, Anfinogenova Y, Popov SV, Kapilevich LV. Exercise and NO production: relevance and implications in the cardiopulmonary system. Front Cell Dev Biol 2015;2:73.

Quayle JM, McCarron JG, Brayden JE, Nelson MT. Inward rectifier K+ currents in smooth muscle cells from rat resistance-sized cerebral arteries. Am J Physiol 1993;265(5 Pt 1):C1363-1370.

Rådegran G, Saltin B. Nitric oxide in the regulation of vasomotor tone in human skeletal muscle. Am J Physiol 1999;276(6 Pt 2):H1951-1960.

Remensnyder JP, Mitchell JH, Sarnoff SJ. Functional sympatholysis during muscular activity. Observations on influence of carotid sinus on oxygen uptake. Circ Res 1962;11:370-380.

Richardson RS, Poole DC, Knight DR, Kurdak SS, Hogan MC, Grassi B, Johnson EC, Kendrick KF, Erickson BK, Wagner PD. High muscle blood flow in man: is maximal $\mathrm{O}_{2}$ extraction compromised? J Appl Physiol (1985) 1993;75:1911-1916.

Saltin B, Mortensen SP. Inefficient functional sympatholysis is an overlooked cause of malperfusion in contracting skeletal muscle. J Physiol 2012;590:6269-6275.

Schrage WG, Joyner MJ, Dinenno FA. Local inhibition of nitric oxide and prostaglandins independently reduces forearm exercise hyperaemia in humans. J Physiol 2004;557(Pt 2):599-611.

Schrage WG, Wilkins BW, Johnson CP, Eisenach JH, Limberg JK, Dietz NM, Curry TB, Joyner MJ. Roles of nitric oxide synthase and cyclooxygenase in leg vasodilation and oxygen consumption during prolonged low-intensity exercise in untrained humans. J Appl Physiol (1985) 2010;109:768-777.

Segal SS, Duling BR. Flow control among microvessels coordinated by intercellular conduction. Science 1986;234:868-870.

Segal SS, Jacobs TL. Role for endothelial cell conduction in ascending vasodilatation and exercise hyperaemia in hamster skeletal muscle. J Physiol 2001;536(Pt 3):937-946.

Sejersted OM, Hargens AR, Kardel KR, Blom P, Jensen O, Hermansen L. Intramuscular fluid pressure during isometric contraction of human skeletal muscle. J Appl Physiol Respir Environ Exerc Physiol 1984;56: 287-295.

Thomas GD. Functional sympatholysis in hypertension. Auton Neurosci 2015;188:64-68.

Thomas GD, Segal SS. Neural control of muscle blood flow during exercise. J Appl Physiol (1985) 2004;97:731-738.

VanTeeffelen JW, Segal SS. Interaction between sympathetic nerve activation and muscle fibre contraction in resistance vessels of hamster retractor muscle. J Physiol 2003;550(Pt 2):563-574.

Welsh DG, Segal SS. Coactivation of resistance vessels and muscle fibers with acetylcholine release from motor nerves. Am J Physiol 1997;273(1 Pt 2):H156-163. 